\title{
LITERATURAS DIGITAIS
}

Alckmar Luiz dos Santos (UFSC)

Everton Vinicius de Santa (UFSC)

Em 2010, o Núcleo de Pesquisas em Informática, Literatura e Linguística (NuPILL) organizou o IV Simpósio de Literatura e Informática, realizado na Universidade Federal de Santa Catarina, um evento que acontece desde 2003 (2003-UERJ, 2005-UFSC, 2007-UEL) e que reúne, desde aquela época, pesquisadores da área da Literatura e Informática no Brasil. Desde o início seu objetivo tem sido discutir as diversas relações entre a literatura e os meios digitais, em suas perspectivas teórica, crítica e prática (esta última entendida como escrita ou criação digital). Isso explica o amplo leque de assuntos tratados: o processamento informática de língua natural, (que compreende tanto a medição estilométrica automática de textos quanto os processos baseados em web-semântica); as bibliotecas e os bancos de dados digitais de literatura; ferramentas de suporte a leitura, ensino e aprendizagem em meio digital (frequentemente associadas às bibliotecas e aos bancos de dados); a criação literária e suas relações com as artes digitais em geral; o tratamento informático de textos literários; o gerenciamento de informação literária na internete; os periódicos literários digitais; a teoria do texto digital; a discussão do papel da literatura no que tem sido chamado de cultura digital etc.

Este dossiê reúne algumas dos trabalhos apresentados e das discussões levantadas no Simpósio de 2010. Entre outros ganhos, ele certamente consolida uma parceria interinstitucional da Universidade Federal de Santa Catariana, e do Núcleo de Pesquisas em Informática, Literatura e Linguística (NuPILL), com outras instituições nacionais e internacionais que atuando efetivamente na tarefa de consolidar a interface Literatura e Informática como campo epistemológico nas Letras e também nas Artes. Assim, a exemplo do que ocorre em todo campo de reflexão que se pretende efetivar dentro de um domínio de grande tradição, como o da literatura, a internacionalização dos debates torna-se imprescindível.

Abrindo o dossiê, temos o ensaio "A verdade está lá fora: pesquisa em literatura na internete", de Alamir Aquino Corrêa, que traz uma discussão interessante sobre os mecanismos e fontes de pesquisa em literatura (mas que podem ser pensados sob outras perspectivas não literárias). Para o autor, a internete é um grande aliado para as pesquisas acadêmicas de todos os níveis e "a área de estudos literários precisa urgentemente rever as suas práticas de pesquisa e de verificação de resultados", considerando o vasto número de 
possibilidades de fontes de consulta de material bibliográfico e literário (aparentemente pouco considerados) frente ao tão cultuado universo do mundo impresso, pretenso "depositário de verdades", como argumenta.

Em "Notícia da atual literatura brasileira digital", de Alckmar Luiz dos Santos e de Cristiano de Sales, temos uma discussão sobre a heterogeneidade em torno da expressão literatura digital, buscando compreendê-lo na perspectiva da crítica e da produção de literatura digital no País. Os autores buscam desenvolver um exercício crítico sobre vertentes de produções literárias que "estão impondo outra forma de entendermos suas poéticas, não só à luz de suas técnicas artísticas e estéticas específicas, mas, agora também, a partir de suas condições de contorno tecnológicas". Percorrendo o caminho de algumas produções atuais da literatura digital, os autores levantam questões teórico-críticas e apontam para terrenos ainda movediços e em construção, tentando esboçar o que poderia ser uma tradição literária no mundo digital.

Carlos Maciel nos apresenta seu ensaio "Legitimação e legitimidade". De que fala ele aî? Da situação brasileira no século XVI, utilizando para isso a estatística linguística. Para ele, a palavra "invasão", muitas vezes utilizada quando das comemorações dos 500 anos do descobrimento, torna-se objeto de análise em seu estudo dos escritos chamados "fundadores", assim como dos elementos que podem caracterizar uma "legitimidade portuguesa" frente ao que virá depois, no cenário da literatura brasileira. Entre essas obras, do acervo da Biblioteca Nacional do Rio de Janeiro e caracterizadas como "Documentos fundadores da história do Brasil", estão a Carta de Pero Vaz de Caminha, as Relação do Piloto Anônimo, o documento deixado por Mestre João Faras e o Tratado da Terra do Brasil, de Pero de Magalhães Gândavo. O autor utiliza o programa Hyperbase para a leitura e a análise desse corpus, buscando entender, através da medição estilística, o processo histórico e constitutivo de identidades nacionais, do Brasil e de Portugal.

Em "Breve análise de narrativas literárias digitais", Cláudia Grijó Vilarouca traz uma reflexão interessante sobre aquilo que obsevamos e chamamos de literatura no meio digital, em contraste com o que distinguimos como impresso. Para a autora, é preciso refletir sobre até que ponto novas possibilidades proporcionadas pelo meio digital modificam o que chamamos de literatura e se, ainda, ela se difere realmente daquela produzida em meio impresso. Recorrendo a três narrativas literárias digitais, Vilarouca levanta questões com respeito ao leitor nesse meio digital, apontando para uma ilusão de liberdade de leitura, quando, na verdade, segundo ela, há uma "ampliação de horizontes de sentido da obra". Afinal, a narrativa ainda precisa de limites estipulados pelo autor. 
Em "A evolução da literatura infanto-juvenil na cibercultura: reflexões a partir da semiótica evolutiva da cultura", Edgar Roberto Kirchof traça uma leitura a partir do semioticista da cultura Walter A. Koch, para tratar de uma interessante reflexão acerca da literatura infanto-juvenil contemporânea e de sua relação com os meios digitais. A proposta apresenta uma leitura evolutiva das formas de linguagem e dos gêneros propiciados pelas práticas virtuais, que possibilitaram o desenvolvimento de outros gêneros. Para Kirchof, há uma tendência literária "moderna e pós-moderna" que cria estruturas mais compactas sob formas mais compostas, agregando sobretudo novas formas, linguagens e códigos, ligados aos sistemas midiáticos. Em função disso é que se percebe a existência de vários autores contemporâneos realizando experimentações literárias ligadas aos novos meios e tecnologias digitais, o que inclui livros infanto-juvenis cujas composições "revelam uma composição evidente realizada a partir de códigos semióticos típicos da ciberesfera".

O trabalho "Representações do eu no ciberespaço: autobiografia e blogues", de Everton de Santa, é uma leitura que parte do pressuposto de que o acesso aos ambientes virtuais faz crescer cada vez mais o número de pessoas sujeitas à imersão de seus 'eus' nesse ciberespaço. Nesse caso, os blogues pessoais são as ferramentas que nos permitem visualizar espaços de auto-representação e autoexposição da figura de si, revelando uma tendência ao espetáculo presente na contemporaneidade. Neste escrito, se procura demonstrar a influência do ciberespaço no processo de construção de identidades de autores de blogues, revelando um discurso marcado pelo autobiográfico e pelo autoficcional, aquele que caminha entre real e ficcional. Ao mesmo tempo, essa reflexão permite trazer à tona algumas questões acerca da memória, sob um viés que caracteriza grande parte das práticas de literatura nos meios virtuais e que vem se concretizar por meio das práticas de escrita em meio digital.

“O texto eletrônico hipertextualizado: a máquina, o autor e o leitor”, de Emanoel Cesar Pires de Assis e de Saulo Brandão, apresenta uma discussão sobre o papel do autor e do leitor do texto digital. Os autores discutem acerca dos novos tipos de leitores promovidos pela leitura na tela, ao mesmo tempo em que questionam a existência de um novo tipo de autor para as "narrativas digitais" (levando em conta o que chamam de nãounilateralidade do texto). O (hiper)texto atravessa todos esses conceitos ligados à literatura e são redimensionados à medida em que se pensa sobre os elementos que constituem esse espaço. Segundo eles, há uma interligação entre autor e leitor, na medida em que não se pode afirmar uma não existência autoral, pois, afinal, a leitura hipertextual sempre segue 
pré-requisitos elaborados pelo autor, mesmo que o leitor a realize de modo diferente do "planejado".

"Três comédias de Shakespeare pela ótica do Stablex - Shakespeare e a informática", de Marly Gondim Cavalcanti Souza, estabelece uma relação analítica lexical, textual e discursiva de três comédias de Shakespeare (Much ado about nothing, As you like it e Twelth night), utilizando uma ferramenta matemático-estatístico-computacional, denominada Stablex, de autoria de André Camlong e Thierry Beltran. A autora envereda pelo aspecto musical presente nas peças, por considerá-lo um dos mais relevantes para a interpretação do leitor e, a partir das evidências apontadas pelas análises matemáticas, estatísticas e algébricas do programa, tenta levantar e explorar todo o vocabulário explorado nas três obras. O intuito da autora, segundo ela, foi "localizar os vocabulários preferenciais e o peso dos itens lexicais relacionados à música, na obra do talvez mais famoso escritor de língua inglesa".

"Em nós: hipertexto e literatura", de Miguel Rettenmaier, há uma reflexão interessante sobre o papel do sujeito leitor na era digital e da relação entre os seres humanos e os computadores. Para o autor, a cibercultura tem em sua base um sujeito movente, conectado e provisório como o próprio ambiente em que estão inseridos autor e leitor, integrados ao que se vai denominar "hipercorpo". Passando por Hayles e Siemens, Rettenmaier aponta para um saber coletivo, em que computadores e seres humanos interagem o tempo todo, sobretudo nesta época em que o acesso à informação está muito mais democrático, graças à internete.

Otávio Guimarães, em "Um LUTHIER digital”, pensa a relação entre criador e obra no meio digital. Por meio de questionamentos desenvolvidos ao longo do seu texto, ele traz à cena a criação artística em meio digital questionando sempre se aquilo que é "novo" (meios e técnicas) seria realmente diferente daquilo que veio antes. Em seu texto, ele estabelece uma relação entre o luthier (aquele que constrói um instrumento ou altera um instrumento de acordo com as necessidades de composição de um músico) e o artista digital. $\mathrm{O}$ autor busca compreender como age a técnica na arte digital, como são utilizados os aparatos ligados ao processo criativo, ao mesmo tempo em que trata da literatura digital e do problema em se pensar numa aparente simplicidade técnica de criação. Com isso, ele não perde de vista que a arte literária não se reduz apenas à técnica, embora não possa prescindir dela.

"Jogos digitais como ferramenta de ensino: reflexões iniciais", de Fernando da Silva e de Sandro Brincher, apresenta algumas considerações com respeito ao uso de jogos como 
ferramenta educacional, discutindo como essa prática pode auxiliar na consolidação de práticas pedagógicas significativas tanto no ensino médio quanto no superior. Tratando do jogo como elemento de significação, associando essa perspectiva a algumas teorias correntes sobre jogo e ludicidade, esse escrito trata de estratégias de incorporação de jogos digitais a planejamentos curriculares e discute a utilização de "jogos como agentes modificadores nas práticas de ensino e aprendizagem", buscando mostrar como essa prática pode oferecer subsídios consistentes para a consolidação de uma prática pedagógica significativa.

Regina Helena M. A. Corrêa encerra nosso dossiê com "Leitoras a escritoras: uma viagem pelo ciberespaço". Por meio de discussões com respeito ao espaço da mulher no cenário literário e social, a autora volta-se para a atualidade do que denomina democratização dos meios eletrônicos que permite a desterritorialização de discursos femininos através do ciberespaço. Este, de fato, tem permitido um amplo acesso à informação, sendo aí tomado como "facilitador do amplo crescimento da escrita feminina no Brasil, nos últimos anos". Assim, seu trabalho envolve busca mapear esse percurso na internete, nas academias e associações virtuais, nas páginas individuais e nos blogues, nos espaços virtuais coletivos utilizados como suporte para escritoras (e não só de literatura).

A variedade de assuntos e de abordagens já revela as riquíssimas discussões que foram travadas durante o Simpósio. Esses trabalhos, aqui, tentam de alguma forma reproduzir o clima de curiosidade, de companheirismo, de congraçamento e de provocação intelectual de que todos desfrutamos. Esperamos que os leitores desse número de Outra Travessia também sintam o mesmo. Bom proveito! 